\title{
Comparison of fast flow and initial slope index values for cerebral blood flow following subarachnoid haemorrhage
}

\author{
PG RICHARDS, T TSUTSUI, L SYMON, A JABRE, J ROSENSTEIN, S REDMOND
}

From the Gough Cooper Dept of Neurological Surgery, Institute of Neurology, Queen Square, London, UK

SUMMARY Forty five patients with subarachnoid haemorrhage proved by lumbar puncture underwent serial measurements of cerebral blood flow and central conduction time. When the initial slope index (ISI) value for cerebral blood flow is considered there is a clear relationship between reduction of cerebral blood flow and deteriorating clinical grade. This relationship is not so clearly demonstrated using the fast flow $\left(f_{1}\right)$ value for cerebral blood flow. When cerebral blood flow is compared to central conduction time those patients with a central conduction time longer than $6.4 \mathrm{~ms}$ have a significantly lower $\mathrm{CBF}_{\text {isi }}$ but not a significant lower $\mathrm{CBFf}_{1}$. Furthermore, using the ISI value, there is a linear relationship between the fall in cerebral blood flow and the lengthening of CCT below a threshold blood flow of about $35 \mathrm{ml} / 100 \mathrm{~g} / \mathrm{min}$. This relationship is not demonstrated with the $\mathrm{CBFf}_{1}$ value. It therefore appears that the ISI value for cerebral blood flow shows a greater correlation between clinical and electrophysiological events than the $f_{1}$ value.

The recent development of portable cerebral blood flow apparatus has made the study of cerebral blood flow in disease states easier. Without moving the patient studies can be made in quick succession by clinical staff at negligible risk to the patient and at an acceptable cost. ${ }^{1}$ In order to determine which value for cerebral blood flow was most useful the fast flow value $\left(f_{1}\right)$ and initial slope index (ISI) were compared in this study with the clinical grade of the patient and central conduction time (CCT).

\section{Patients and methods}

The study was performed on 45 patients, whose ages ranged from 17 to 69 years (mean 50.6 years) who had been admitted to our unit with a diagnosis of subarachnoid haemorrhage proven by lumbar puncture. Eighteen were male and 27 female. All had CT scanning and angiography and were clinically graded by the Hunt and Hess scale ${ }^{2}$ by one of us (LS). Intracranial aneurysms were found in 42 patients, 36 of whom underwent craniotomy and clipping of the aneurysm. Table 1 indicates the site of the aneurysms. Cerebral blood flow (CBF) and somatosensory evoked potential (SSEP) measurements were made in all patients at regular intervals during their hospital stay. For technical reasons

Address for reprint requests: Prof Lindsay Symon, National Hospital for Nervous Diseases, Queen Sq, London WCIN 3BG, UK.

Received 28 December 1984 and in revised form 21 August 1985. Accepted 25 August 1985 recordings could not be made simultaneously and only measurements made within 2 hours of each other were used for comparison. One hundred and seventy seven cerebral blood flow studies were performed, examining a total of 354 hemispheres. Eighty five examinations of CBF and SSEP were comparable, although due to technical difficulties, one hemisphere had to be excluded. Therefore cerebral blood flow and somatosensory evoked potentials could be compared in a total of 169 hemispheres.

Cerebral blood flow was measured at the bedside using intravenous xenon ${ }^{133}$. Detection and calculations were performed using the Novo Cerebrograph 2a (Nova Diagnostic Systems, Bagsvaard, Denmark). An intravenous bolus injection of $10 \mathrm{mCi}$ of xenon ${ }^{133}$ in normal saline was given, emitted radiation being measured by a single scintillation counter overlying the somatosensory cortex in each hemisphere. Expired air was collected and sampled by a close-fitting face mask, or directly from an endotracheal tube in intubated patients. Each study lasted 11 minutes, following which the Cerebrograph calculated the CBF using the Risberg

Table 1 Sites of aneurysms

Posterior communicating artery
Anterior communicating artery
Middle cerebral artery
Carotid bifurcation
Ophthalmic
Basilar bifurcation
Pericallosal
Anterior choroidal
Multiple
Nil found


Table 2 Clinical grade and $C B F$

\begin{tabular}{|c|c|c|c|c|c|c|}
\hline Grade & $\begin{array}{l}\text { No of } C B F \\
\text { studies }\end{array}$ & $\begin{array}{l}\text { Mean } C B F_{\mathrm{isi}}(S D) \\
\mathrm{ml} / 100 \mathrm{~g} / \mathrm{min}\end{array}$ & $\begin{array}{l}\text { Mean } \mathrm{CBFf}_{1}(S D) \\
\mathrm{ml} / 100 \mathrm{~g} / \mathrm{min}\end{array}$ & $C C T(S D) m s$ & $\begin{array}{l}\text { Mean pCO } \\
\text { mmHg }\end{array}$ & $M A P(S D) m m H g$ \\
\hline $\begin{array}{l}\text { I } \\
\text { II } \\
\text { III } \\
\text { IV } \\
\text { V }\end{array}$ & $\begin{array}{r}100 \\
58 \\
120 \\
64 \\
12\end{array}$ & $\begin{array}{l}48 \cdot 6(13 \cdot 3) \\
47 \cdot 6(11 \cdot 1) \\
41 \cdot 0(9 \cdot 3) \\
36 \cdot 1(7 \cdot 4) \\
33 \cdot 2(9 \cdot 9)\end{array}$ & $\begin{array}{l}72.6(21 \cdot 2) \\
73.6(22.4) \\
57.5(16.4) \\
56.5(24 \cdot 1) \\
59.8(27.4)\end{array}$ & $\begin{array}{l}5.6(0.4) \\
5.8(0.2) \\
6.0(0.3) \\
6.6(0.2) \\
7.0(0.4)\end{array}$ & $\begin{array}{l}34 \cdot 0(9 \cdot 2) \\
36 \cdot 5(5 \cdot 8) \\
35 \cdot 4(7 \cdot 1) \\
34 \cdot 7(3 \cdot 7) \\
33 \cdot 5(3 \cdot 7)\end{array}$ & $\begin{array}{c}97.6(9.7) \\
104.1(23.8) \\
103.5(16.7) \\
123.4(18 \cdot 8) \\
119.1(30.7)\end{array}$ \\
\hline
\end{tabular}

Table $3 \quad C B F$ vs $C C T$

\begin{tabular}{|c|c|c|}
\hline$C C T$ & $\begin{array}{l}\text { Mean } C B F_{\mathrm{isi}}(S D) \\
\mathrm{ml} / 100 \mathrm{~g} / \mathrm{min}\end{array}$ & $\begin{array}{l}\text { Mean } C B F f_{1}(S D) \\
\mathrm{ml} / 100 \mathrm{~g} / \mathrm{min}\end{array}$ \\
\hline $\begin{array}{l}<6.4 \\
\geqslant 6.4\end{array}$ & $\begin{array}{l}45 \cdot 6(4 \cdot 1) \\
31 \cdot 1(6 \cdot 5)\end{array}$ & $\begin{array}{l}64 \cdot 0(3 \cdot 99) \\
61 \cdot 1(18 \cdot 3)\end{array}$ \\
\hline
\end{tabular}

modification ${ }^{34}$ of the two compartment model described by Obrist. ${ }^{5}$ Two values of CBF were computed by the Cerebrograph, the $f_{1}$ value and the ISI value. $F_{1}$ is the fast compartment flow, often considered to be the value mainly pertaining to flow through cerebral grey matter. ${ }^{67}$ ISI, the initial slope index, is the monoexponential of the early portion of the xenon desaturation curve between 0.5 and 1.5 minutes, and represents flow through fast and slow compartments, though primarily dominated by the fast compartment. ${ }^{38}$

Somatosensory evoked potential and central conduction time (CCT) recordings were measured using the modification of technique of Hume and Cant, ${ }^{9}$ as described by Wang et al. ${ }^{10}$ Bipolar stimulating electrodes were placed at the median nerve at the wrist and square waves of $0.5 \mathrm{~ms}$ were applied at a rate of $3 \mathrm{H}_{2}$, with an intensity just sufficient to produce a small twitch of the abductor pollicis brevis. Recording electrodes were applied over the spinous process of $\mathrm{C} 2$ and over the somatosensory cortex in both hemispheres in equivalent positions to the cerebral blood flow detectors. The central conduction time, the time between the N14 peak recorded at $\mathrm{C} 2$ and the N20 peak over the somatosensory cortex, was recorded. Recording CCT in 20 normal volunteers gave a mean CCT of $5.4 \pm 0.4 \mathrm{~ms}$. This value plus $2 \cdot 5$ standard deviations was considered abnormal, giving a value of $6.4 \mathrm{~ms}$ or greater as a significantly prolonged CCT. ${ }^{10}$

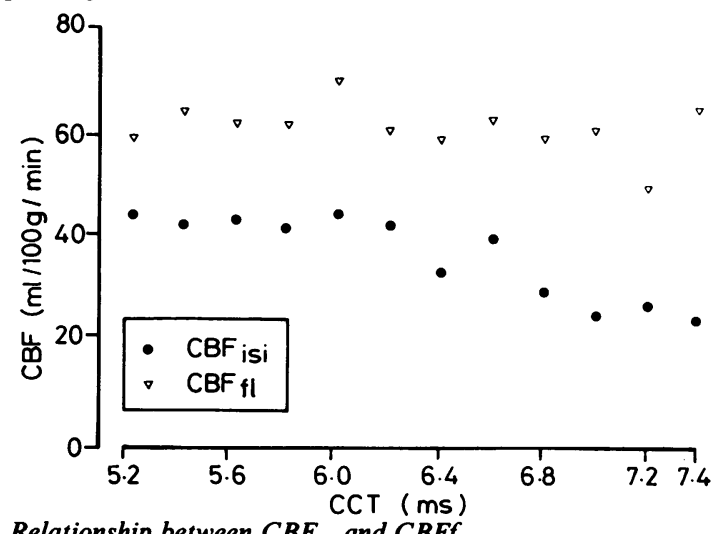

\section{Results}

\section{(1) Clinical grade and $C B F$}

Table 2 shows a relationship between $\mathrm{CBFf}_{1}, \mathrm{CBF}_{\text {isi }}$ and clinical grade in all patients. Comparing ISI values, no statistical difference in flow is seen between grades 1 and 2, or between grades 4 and 5 . There is however a highly significant difference (p 0.001) between grades 2 and 3, and between grades 3 and 4 . The differences between grades of the $f_{1}$ values are not so clearly demonstrated. The only significant difference $(p 0.001)$ is between grades 2 and 3 , there being no statistical difference between grades 1 and 2 , grades 3 and 4, or grades 4 and 5 .

\section{(2) $C B F$ and $C C T$}

Table 3 displays the results of 169 hemisphere recordings of CCT and CBF. The mean $\mathrm{CBF}_{\text {isi }}$ in the $135^{\circ}$ hemispheres showing a CCT of less than $6.4 \mathrm{~ms}$ is $45.6 \mathrm{ml} / 100 \mathrm{~g} / \mathrm{min}$ (SD 4.1) whereas in the $34 \mathrm{hemi}-$ spheres where CCT is greater than or equal to $6.4 \mathrm{~ms}$, the mean $\mathrm{CBF}_{\text {isi }}$ is $31 \cdot 1 \mathrm{ml} / 100 \mathrm{~g} / \mathrm{min}$ (SD 6.5). This difference is significant at the $1 \%$ level using Student's $t$ test. The CBFf, values however are not significantly different. The mean value of $\mathrm{CBFf}_{1}$ for hemispheres with a CCT of less than $6.4 \mathrm{~ms}$ is 64.0 (SD 3.99), whereas for hemispheres with a CCT greater than or equal to $6.4 \mathrm{~ms}$ it is $61.1 \mathrm{ml} / 100 \mathrm{~g} / \mathrm{min}$ (SD 18.3). The figure displays graphically CBF versus CCT. Here it can be seen that when looking at $\mathrm{CBF}_{\text {isi }}$ values there is a progressive diminution in cerebral blood flow as the CCT lengthens beyond $6.4 \mathrm{~ms}$ This progressive reduction of $\mathrm{CBF}_{\mathrm{isi}}$ appears to show a linear relationship with the progressive lengthening of CCT. No such relationship was demonstrated with the fast flow values. A threshold flow above which central conduction time is independent of cerebral blood flow, but below which the central conduction times prolong in a linear relationship to the fall in cerebral blood flow is demonstrated using the ISI value. This threshold lies around $30 \mathrm{ml} / 100 \mathrm{~g} / \mathrm{min}$. No threshold is demonstrated using the $f_{1}$ values.

\section{Discussion}

The development of techniques of measuring CBF

Relationship between $C B F_{i s i}$ and $C B F f_{1}$ 
indicated that three separate compartments are measurable, the fast flow cerebral tissues, the slow flow cerebral tissues and the extracerebral tissues. ${ }^{11}$ By presenting the washout curves as a biexponential curve, the fast flow could be separately measured. This has been felt to represent in the main grey matter flow. ${ }^{5}$ The initial slope index is a monoexponential slope in the early part of the xenon washout curve ${ }^{38}$ and this is calculated on the Cerebrograph on the portion of the curve between 0.5 and 1.5 minutes.

The ISI was developed to overcome several practical and theoretical disadvantages of the biexponential method of calculating CBF. It had been noted that the values of the fast flow tended to fluctuate, the fluctuation being associated with variation in a relative "weight" of the grey matter compartment. $^{3}$ These variations may be due to actual anatomical change in the grey matter, such as following infarct or atrophy. ${ }^{7}$ The more probable explanation however is that the $f_{1}$ compartment does not represent homogeneous grey matter, but includes grey matter with fast flow, grey matter with slow flow and white matter with fast flow. Depending upon physiological and pathological conditions, the latter two tissues may fluctuate between the measured slow and fast flow compartments. ${ }^{3}$ The ISI is dominated by the flow from fast clearing tissues. ${ }^{8}$ Risberg has calculated that $84 \%$ of the counts analysed in the initial part of the curve originate from the fast compartment. ${ }^{3}$ The third compartment, primarily very slowly clearing extracerebral tissue such as scalp, has a negligible effect on the early part of the curve ${ }^{6}$ and it may therefore be assumed that the ISI is an index of cortical flow with little or no extracerebral contamination. The ISI is not subject to great fluctuation and is independent of variation in the relative proportion of "weight" of the fast or slow flow compartments. ${ }^{3-5}$

Central conduction time has been shown to be a useful indicator of ischaemia following subarachnoid haemorrhage. ${ }^{1012}$ It has been shown that below a critical threshold for cerebral blood flow there is a severe disturbance of cerebral function, as shown by prolongation of central conduction time or reduction in amplitude of evoked potential. ${ }^{13-15}$ It has also been shown in the baboon that below this critical level, the prolongation of CCT has an exponential relationship with the reduction in cerebral blood flow. ${ }^{16}$

Our results in this study support the value of ISI. There is stronger correlation between the ISI and the clinical grade than between $f_{1}$ and clinical grade. Likewise, when comparing CCT and CBF, there is a clear diminution in flow as CCT prolongs beyond $6.4 \mathrm{~ms}$ when comparing CCT and ISI, which is not shown when comparing CCT and $f_{1}$ flows. No threshold value below which CCT prolongs in a linear relationship with reduction in cerebral blood flow is demonstrated using the $f_{1}$ values, whereas using the ISI values a threshold is demonstrated at around $35 \mathrm{ml} / 100 \mathrm{~g} / \mathrm{min}$. It therefore appears that ISI reflects clinical and electrophysiological events better than $f_{1}$.

A further advantage of using the ISI is that steady state need only be achieved for the first few minutes after injection. When using $f_{1}$ a steady state needs to be maintained throughout the whole 11 minutes of the measurement. In a cooperative patient this is not a problem, but in the restless patient it may be difficult to achieve.

As bedside cerebral blood flow monitoring becomes more widespread it therefore appears that the ISI value should be adopted in view of its reproducibility and its correlation with clinical grade and CCT.

The authors thank Sarah Chittenden for typing the manuscript.

\section{References}

${ }^{1}$ Rosenstein J, Suzuki M, Symon. L, Redmond S. Clinical use of portable bedside cerebral blood flow measurements in the management of aneurysmal subarachnoid haemorrhage. Neurosurgery 1984;15(4):519-25.

${ }^{2}$ Hunt WE, Hess RM. Surgical risk as related to time of intervention in the repair of intracranial aneurysms. $J$ Neurosurg 1968;28:14-20.

${ }^{3}$ Risberg J, Ali Z, Wilson EM, Willis EL, Halsey JH Jr. Regional cerebral blood flow measurements by ${ }^{133}$ Xenon inhalation. Preliminary evaluation of an initial slope index in patients with unstable flow compartments. Stroke 1975;6:142-8.

${ }^{4}$ Risberg J. Regional cerebral blood flow measurements by 133-Xenon inhalation: Methodology and applications in neuropsychology and psychiatry. Brain Lang 1980;9:9-34.

${ }^{5}$ Obrist WD, Thompson HK Jr, Wang HS, Wilkinson WE. Regional cerebral blood flow estimated by ${ }^{133}$ xenon inhalation. Stroke 1975;6:245-56.

${ }^{6}$ Wollman H, Alexander SC, Cohen PJ, Stephen GW, Zeiger LS. Two-compartment analysis of the blood flow in the human brain. Acta Neurol Scandinav 1965;Suppl 14:79-82.

${ }^{7}$ Høedt-Rasmussen K, Skinhøj E. In vivo measurements of the relative weights of gray and white matter in the human brain. Neurology (Minneap) 1966;16:515-20.

${ }^{8}$ Doyle TF, Martins AN, Kobrine AI. Estimating total cerebral blood flow from the initial slope of hydrogen washout curves. Stroke 1980;6:149-52.

${ }^{9}$ Hume AL, Cant BR. Conduction time in cerebral somatosensory pathways in man. Electroencephalalogr Clin Neurophysiol 1978;45:361-75.

${ }^{10}$ Wang AD, Cone J, Symon L, Costa E, Silva IE. Somatosensory evoked potential monitoring during the management of aneurysmal subarachnoid haemorrhage. J Neurosurg 1984;60:264-8. 
${ }^{11}$ Obrist WD, Thompson HK Jr, King CH. Determination of regional cerebral blood flow by inhalation of 133-Xenon. Circulation Res 1967;20:124-35.

${ }^{12}$ Symon L, Hargadine J, Zawirski M, Branston NM. Central conduction time as an index of ischaemia in subarachnoid haemorrhage. J Neurol Sci 1979;44:95-103.

${ }^{13}$ Astrup J, Symon L, Branston NM, Lassen NA. Cortical evoked potential and extracellular $\mathrm{K}^{+}$and $\mathrm{H}^{+}$at critical levels of brain ischemia. Stroke 1977;8:51-7.

${ }^{14}$ Branston NM, Symon L, Crockard HA, Pasztor E.
Relationship between the cortical evoked potential and local cortical blood flow following acute middle cerebral artery occlusion in the baboon. Exp Neurol 1974;45:195-208.

${ }^{15}$ Heiss WD, Hakawaya T, Waltz AG. Cortical neuronal function during ischaemia. Arch Neurol 1976;33: 813-20.

${ }^{16}$ Hargadine JR, Branston NM, Symon L. Central conduction time in primate brain ischaemia: a study in baboons. Stroke 1980;11:637-43. 